\title{
Case Report Frontal lobe neuropathology presenting to Mental Health Services
}

\author{
Miyuru Chandradasa ${ }^{1}$, Silumini de Silva ${ }^{2}$, Layani C Rathnayake ${ }^{2}$, Chirantha Sanjeewa \\ Kuruppuarachchi ${ }^{3}$, K A L A Kuruppuarachchi ${ }^{1}$ \\ ${ }^{1}$ Faculty of Medicine, University of Kelaniya, ${ }^{2}$ Colombo North Teaching Hospital, ${ }^{3}$ Kothalawela \\ Defense University, Sri Lanka
}

\section{Keywords: Frontal lobe; Neuropsychiatry; Seizures; Psychopathology; Sri Lanka; Mental Health}

\author{
Corresponding Author: Miyuru Chandradasa, E-mail: < miyuruc@kln.ac.lk > iD https://orcid.org/0000-0002-1873-8228 \\ Submitted: November 2019, Accepted: June 2020, Published June 2020 \\ Competing Interests: Authors have declared that no competing interests exist \\ (C) Authors. This is an open-access article distributed under a Creative Commons Attribution-Share \\ Alike 4.0 International License (CC BY-SA 4.0), which permits unrestricted use, distribution, and \\ reproduction in any medium, provided the original author and source are attributed and materials \\ are shared under the same license.
}

\section{Introduction}

The complexity of the function and structure of the frontal lobe contributes to the varying presentation of frontal lobe pathologies to neurology and psychiatry specialities. Frontal lobe epilepsy has been identified in clinical practice for many decades and seems to be the second most common form of focal epilepsy [1]. However, diagnosis remains a challenge, and it is considered to be one of the least understood forms of epilepsy. When seizures occur due to frontal lobe pathology, the electrical charge spreads rapidly and widely. This makes localisation of the focus difficult during the interictal phase. Due to the rapid spread of seizure activity, the clinical presentations during the ictal and interictal phases could be diverse and challenging to interpret. In addition, the electroencephalographic (EEG) findings could be normal in the ictal and interictal phases and neuroimaging findings could be unrevealing, adding to the diagnostic dilemma $[2,3]$.

Complex clinical presentations due to frontal lobe neuropathology could present to mental health services. The clinicians working in psychiatric services must have the skills and expertise to identify and refer these neurological abnormalities promptly. A missed diagnosis or a delayed referral in frontal lobe neuropathology could lead to significant morbidity and mortality. Here, we describe three patients presenting to the specialised psychiatric services of the Colombo North Teaching Hospital in Ragama Sri Lanka and later identified to have focal frontal lobe pathology. We aim to highlight the importance of clinical acumen in neurology, so as to diagnose these complex presentations in mental health settings. Informed written consent for publication was obtained from the patients.

\section{Case Summaries}

The first patient is Mrs A*, a right dominant, 32-year-old Sri Lankan female. She had been followed up by the mental health services for a delusional disorder of the jealousy type for several months. In a follow-up visit to the outpatient services, her delusional beliefs were not present after treatment with aripiprazole. Further, she revealed that she was suffering from a tingling sensation in her distal right lower limb spreading towards the thigh when about to reach an orgasm during sexual intercourse, which was very uncomfortable for her. This had occurred on several occasions over the previous four years. This uncomfortable 
sensation had made her reluctant to engage in sexual activity. Her reluctance had been misinterpreted as a symptom of her psychiatric ailment. The detailed neurological examination was normal. Her interictal EEG showed irregular frontal lobe spikes and waves, more prominent on the left side, that were reported by a neurologist as likely to be due to a focal frontal lobe pathology. Magnetic resonance imaging (MRI) of the brain did not find any structural abnormalities. Although her delusional symptoms resolved completely with aripiprazole, she continued to suffer from the unusual sensations during sexual intercourse until sodium valproate was added. At six months' follow up, she remained free from psychiatric and neurological symptoms.

The second patient is $\mathrm{Mr} \mathrm{B*}$, a 50-year-old, right dominant male, heavy smoker who presented with jerky movements in his right upper limb which spread to the right lower limb with kicking movements. There was no loss of consciousness during these episodes and there was no past history of a medical disorder. The family brought him to the mental health services interpreting these movements as abnormal behaviour related to a mental disorder. He had experienced these episodic movements two to three times per week, over two years. Neurological examination did not reveal any abnormalities. Mr B's inter-ictal EEG was found to be a typical trace. MRI of the brain showed an old cortical infarct of about $1 \mathrm{~cm}$ in width in the motor area of the left frontal lobe. He was referred to the neurologist and the frequency of seizures reduced with treatment with the anticonvulsant sodium valproate. At six months' follow up he was attending to his day to day activities with a reduced frequency of episodic movements.

The third patient, Mrs C*, a 26-year-old, right dominant Sri Lankan female was seen at the psychiatric services due to developing an episodic seizure-like activity. These episodes occurred with significant depressive symptomatology in the context of multiple psychosocial stressors. She was first suspected of suffering from dissociative seizures. Further exploration of symptoms revealed that she was suffering from intermittent jerky movements of the left upper limb which led to her dropping objects from her left hand, followed by transient weakness. These symptoms had been present over the previous year with the occurrence of episodic movements three times per month, on average. Physical examination and the interictal EEG were found to be normal. MRI of the brain showed a calcified aneurysm in her right frontal lobe in the territory of the middle cerebral artery. Mrs $C$ was referred for neurosurgical opinion and it was decided not to go ahead with cranial surgery. She was commenced on the anticonvulsant carbamazepine in addition to her psychotherapeutic and antidepressant treatment with sertraline. At six months' follow up, she was functioning as a homemaker without significant neurological or psychiatric symptomatology. The biochemical and haematological parameters in all three patients were within normal limits.

\section{Discussion}

The case reports describe three patients presenting to mental health services in Sri Lanka with focal frontal lobe pathology and neurological manifestations. A young female diagnosed with delusional disorder presented with tingling sensations in the distal right lower limb spreading towards the thigh during sexual intercourse. A middle-aged male presented with focal convulsions spreading from the right upper to lower limb and was later detected to have an old cerebral infarct in the left frontal lobe. Another young female, suspected of having dissociative symptoms, presented with episodic seizure-like activity. These case reports 
demonstrate how focal frontal pathology could present to psychiatric services and the need for detailed neurological assessment in mental health settings.

A young female with seizure activity related to sexual intercourse has been previously reported from Turkey. Similar to Mrs A, this patient was also found to have a normal MRI scan and predominantly left frontotemporal spikes and waves in the EEG [4]. However, seizure activity associated with sexual phenomena has been described with right hemisphere foci in most published cases [4]. In a case series of patients with delusional jealousy, it was found that most patients with structural lesions had right frontal lobe pathology [5].

Silent cerebral infarcts were found frequently among psychiatric patients with cognitive dysfunction in Bosnia and Herzegovina [6]. Mr B was suspected of having a mental disorder by the family despite having no past history. The exact timeline of his old cerebral infarct is not known. Among a group of patients who developed late seizures following cerebral infarcts, it was found that simple partial and motor seizures accounted for $80 \%$ of classifiable seizures [7]. Likewise, Mr B developed a simple partial motor seizure without loss of consciousness. Despite $\mathrm{Mr} \mathrm{B}$ developing a neurological disorder, he was brought by his relatives to the mental health services. Knowledge about the presentation of altered mental health may be lacking in a significant proportion of the population and even major psychiatric disorders such as schizophrenia may present to the clinical services after years of symptoms [8].

Mrs C was initially suspected of having a dissociative seizure, considering the psychosocial context of her presentation. Psychogenic non-epileptic seizures (PNES) are not associated with any abnormal electrical activity of the brain [9]. Mrs C was found to have a normal EEG. PNES commonly manifest between the ages 15 to 30 years and three-quarters of patients are females $[9,10]$. Mrs C fitted into the classical picture of a young female with psychosocial stressors presenting with episodic seizure-like activity. Further clinical exploration revealed focal neurological features, leading to her being referred for neuroimaging studies. Unruptured intracranial aneurysms are usually not associated with seizures. However, there have been reports of seizures associated with right middle cerebral artery aneurysms as in Mrs C [11]. It is doubtful whether the intracranial aneurysm in Mrs C was directly related to her clinical presentation. However, an incidental finding of a cerebral aneurysm in a British woman with a depressive illness has been reported [12].

Economic limitations play a significant role in a clinician's decision to order neuroimaging in resource-limited settings, which is seen even in children with epilepsy [13]. Therefore, the assessing clinician needs to have a high degree of clinical acumen to obtain the maximum benefit to the patient and the system.

At present, there is a mandatory neurology rotation for post-MD trainees in psychiatry in Sri Lanka. This training allows the advanced trainee to sharpen his/her clinical skills in identifying potential neurological abnormalities that could present to acute mental health settings. The above case reports show how neuropathologies, such as focal frontal lobe pathology, could present first to a psychiatrist. These cases justify the importance of continuing the mandatory neurology rotation for trainee psychiatrists in Sri Lanka and other countries. 
In conclusion, focal frontal lobe pathology could present to mental health services with diverse clinical presentations. A detailed neurological assessment and high clinical acumen in the psychiatrist is vital to identify the need for further investigations or referral to other specialities. Clinical judgment is essential in any setting but even more in resource-limited settings where advanced investigations have economic limitations.

\section{References}

1. Englot DJ, Wang DD, Rolston JD, Shih TT, Chang EF. Rates and predictors of long-term seizure freedom after frontal lobe epilepsy surgery: a systematic review and meta-analysis. Journal of neurosurgery. 2012; 116:1042-8. https://doi.org/10.3171/2012.1.JNS111620

2. Williamson PD, Spencer DD, Spencer SS, Novelly RA, Mattson RH. Complex partial seizures of frontal lobe origin. Ann Neurol 1985; 18: 497-504. https://doi.org/10.1002/ana.410180413

3. Swartz BE, Halgren E, Delgado-Escueta A, et al. Neuroimaging in patients with seizures of probable frontal lobe origin. Epilepsia 1989; 30: 547-558. https://doi.org/10.1111/j.1528-1157.1989.tb05470.x

4. Ozkara C, Ozdemir S, Yilmaz A, Uzan M, Yeni N, Ozmen M. Orgasm-induced seizures: a study of six patients. Epilepsia. 2006; 47:2193-7. PubMed PMID: 17201724. https://doi.org/10.1111/j.1528-1167.2006.00648.x

5. Graff-Radford J, Whitwell JL, Geda YE, Josephs KA. Clinical and imaging features of Othello's syndrome. Eur J Neurol. 2012; 19:38-46. doi: 10.1111/j.1468-1331.2011.03412.x. Epub 2011 Apr 25. PubMed PMID: 21518145; PubMed Central PMCID: PMC3144984. https://doi.org/10.1111/j.1468-1331.2011.03412.x

6. Lin CY, Oveisi S, Burri A, Pakpour AH. Theory of Planned Behavior, including self-stigma and perceived barriers, explain help-seeking behaviour for sexual problems in Iranian women suffering from epilepsy. Epilepsy Behav. 2017 https://doi.org/10.1016/j.yebeh.2017.01.010

7. Awada A, Omojola MF, Obeid T. Late epileptic seizures after cerebral infarction. Acta Neurol Scand. 1999; 99:265-8. PubMed PMID: 10348154. https://doi.org/10.1111/j.1600-0404.1999.tb00674.x

8. Chandradasa M, Champika L, Gunathillaka K, Mendis J. Association of duration of untreated psychosis and functional level, in first episode of schizophrenia attending an outpatient clinic in Sri Lanka. Journal of the Postgraduate Institute of Medicine. 2016;3(E33):pp.1-6. https://doi.org/10.4038/jpgim.8112

9. Brown RJ, Reuber M. Psychological and psychiatric aspects of psychogenic non-epileptic seizures (PNES): A systematic review. Clin Psychol Rev. 2016 https://doi.org/10.1016/j.cpr.2016.01.003

10.Reuber M. Psychogenic nonepileptic seizures: answers and questions. Epilepsy Behav. 2008 https://doi.org/10.1016/j.yebeh.2007.11.006

11.Sena JC, Reynier Y, Alliez B. Unruptured intracranial aneurysm presenting with epileptic seizure. Arquivos de neuro-psiquiatria. 2003 Sep;61(3A):6637. https://doi.org/10.1590/S0004-282X2003000400026 
12. Beumont PJ. The familial occurrence of berry aneurysm. Journal of neurology, neurosurgery, and psychiatry. 1968; 31:399-402. https://doi.org/10.1136/jnnp.31.4.399

13.Sanmaneechai O, Danchaivijitr N, Likasitwattanakul S. Predictors of Abnormal Neuroimaging of the Brain in Children with Epilepsy Aged 1 Month to 2 Years: Useful Clues in a Resource-Limited Setting. J Child Neurol. 2015 https://doi.org/10.1177/0883073815574199 